\title{
Implementing Electronic Tablet-Based Education of Acute Care Patients
}

Tenita Sawyer, RN

Monica J. Nelson, RN, MSN

Vickie McKee, RN

Margaret T. Bowers, RN, DNP, FNP-BC, CHFN

Corilin Meggitt, RN, MSN

Sarah K. Baxt, RN, BSN

Delphine Washington, RN, BSN
Louise Saladino, RN, DNP, MHA, CCRN

E. Philip Lehman IV, MD, MPP

Cheryl Brewer, RN, MSN, PhD

Susan C. Locke, PhD

Amy Abernethy, MD, PhD

Catherine L. Gilliss, RN, PhD

Bradi B. Granger, RN, MSN, PhD

Poor education-related discharge preparedness for patients with heart failure is believed to be a major cause of avoidable rehospitalizations. Technology-based applications offer innovative educational approaches that may improve educational readiness for patients in both inpatient and outpatient settings; however, a number of challenges exist when implementing electronic devices in the clinical setting. Implementation challenges include processes for "on-boarding" staff, mediating risks of cross-contamination with patients' device use, and selling the value to staff and health system leaders to secure the investment in software, hardware, and system support infrastructure. Strategies to address these challenges are poorly described in the literature. The purpose of this article is to present a staff development program designed to overcome challenges in implementing an electronic, tablet-based education program for patients with heart failure. (Critical Care Nurse. 2016;36[1]:60-70)

\footnotetext{
lthough many factors contribute to high rates of hospital readmission for patients with heart failure, inadequate educational preparation for discharge is one factor that is largely 1 avoidable and predominantly managed by nurses. ${ }^{1,2}$ New electronic, tablet- based patient education platforms, designed to address predischarge gaps in education, are increasingly accessible and linked to electronic health records. ${ }^{3,4}$ Yet, integrating these tools into nursing workflow is challenging. Staff development initiatives to facilitate adoption of electronic tablet-based patient education in the acute care setting are needed.
}

\section{CE 1.0 hour}

This article has been designated for CE contact hour(s). The evaluation tests your knowledge of the following objectives:

1. Identify 3 outcomes for measuring successful implementation of tablet-based education into clinical practice settings

2. Describe a method for preventing microbial cross-contamination when using technology-based educational devices between patients

3. Discuss the roles of 3 multidisciplinary team members in implementation of technology-based patient education in the clinical setting

To complete evaluation for CE contact hour(s) for test \#C1613, visit www.ccnonline.org and click the "CE Articles" button. No CE test fee for AACN members. This test expires on February 1, 2019.

The American Association of Critical-Care Nurses is an accredited provider of continuing nursing education by the American Nurses Credentialing Center's Commission on Accreditation. AACN has been approved as a provider of continuing education in nursing by the State Boards of Registered Nursing of California (\#01036) and Louisiana (\#LSBN12).

C2016 American Association of Critical-Care Nurses doi: http://dx.doi.org/10.4037/ccn2016541 
To illustrate the gravity of the prevalence and high cost of preventable readmissions, the Agency for Healthcare Research and Quality sponsored work to identify contributing factors. Of the 9 million Medicare hospitalizations yearly, 1 in 5 patients is readmitted within 1 month of discharge. ${ }^{5}$ The cost of hospital readmissions is estimated to be $\$ 26$ billion per year, of which $\$ 17$ billion is considered preventable. ${ }^{5}$ Notably, inadequate educational preparation was identified as a common contributor to avoidable readmissions and was established as a target for care redesign. ${ }^{6-8}$ In 2009 , providing

\section{Authors}

Tenita Sawyer is a clinical nurse at the Duke Heart Center, Duke University Health System, Durham, North Carolina.

Monica J. Nelson is a nurse at the University of North Carolina at Chapel Hill School of Nursing, Chapel Hill, North Carolina.

Vickie McKee is a clinical nurse at the Duke Heart Center, Duke University Health System.

Margaret T. Bowers is an assistant professor at the Duke University School of Nursing and Duke University Health System, Durham, North Carolina.

Corilin Meggitt is a nurse at the Duke University School of Nursing.

Sarah K. Baxt is a nurse at the Duke University School of Nursing.

Delphine Washington is nurse manager, education, cardiology nursing, Duke Heart Center, Duke University Health System.

Louise Saladino is clinical operations director, cardiology nursing, Duke Heart Center, Duke University Health System.

E. Philip Lehman IV is a fellow in cardiovascular disease at the Department of Medicine, Duke University School of Medicine, Durham, North Carolina.

Cheryl Brewer is manager of clinical trials operations and project management, Duke Cancer Care Research Program/Center for Learning Health Care, Duke Clinical Research Institute, Durham, North Carolina.

Susan C. Locke is senior scientist and project leader at the Center for Learning Health Care, Duke Clinical Research Institute.

Amy Abernethy is director of the Duke Center for Learning Health Care and a professor in the Duke University Department of Medicine and School of Nursing.

Catherine L. Gilliss is dean of the Duke University School of Nursing.

Bradi B. Granger is director of the Duke Heart Center Nursing Research Program and an associate professor in the Duke University School of Nursing.

Corresponding author: Bradi B. Granger, RN, MSN, PhD, FAAN, Duke University School of Nursing, Box 3943, Durham, NC 27710 (e-mail: grang004@mc.duke.edu).

To purchase electronic or print reprints, contact the American Association of Critical-Care Nurses, 101 Columbia, Aliso Viejo, CA 92656. Phone, (800) 899-1712 or (949) 362-2050 (ext 532); fax, (949) 362-2049; e-mail, reprints@aacn.org. written instructions and educational materials at discharge became a critical performance measure in the heart failure clinical practice guidelines for the American College of Cardiology and American Heart Association. ${ }^{9}$ The Joint Commission and the Centers for Medicare and Medicaid Services also require that discharge instructions include information on medications, worsening symptoms, diet, activity, weight monitoring, and follow-up appointments. ${ }^{10-12}$ Although clinical practice guidelines and regulatory requirements support the need for more effective education before discharge, the challenges of redesigning traditional paper-based educational content and patient education workflow processes in inpatient care settings are substantial.

For nurses, classroom education is shifting to include more contemporary, pedagogically appropriate approaches, moving from static text-based methods to more interactive visual and skill-based modes of education available on electronic platforms. ${ }^{13}$ Increasingly, education for patients is also following these trends, gradually incorporating audiovisual content and more interactive technology-based modes of delivery. ${ }^{14}$ Using electronic platforms, or mobile technology, to deliver patient education in the predischarge phase of care provides a new opportunity to improve predischarge educational preparedness by evaluating the learning that takes place during hospitalization. Electronic platforms improve the interactive capabilities of standard patient education, and some web-based electronic platforms allow nurses to support patients' ongoing educational needs beyond the inpatient setting, communicating needs with nurses in the clinic and even in the home. ${ }^{4}$

Because of these advantages, mobile technologies, defined for the purpose of this article as electronic tabletor smart phone-based platforms, are quickly becoming a more accepted approach for patient education. ${ }^{15}$ Studies have explored the potential for e-learning and mobile technology to improve educational outcomes, particularly in patients with chronic illnesses such as cancer, asthma, and diabetes. ${ }^{16,17}$ These studies have shown that the use of mobile technologies has improved patient engagement, ${ }^{18}$ decreased postdischarge complications, ${ }^{19}$ and improved communication. ${ }^{20}$ Technology-based applications have demonstrated the potential to change the approach for teaching self-management by equipping patients with the knowledge and tools to better manage chronic illness. ${ }^{21}$ Traditional patient-teaching 
materials used by health care providers can be printheavy with few graphics or illustrations, but technology-based approaches are more engaging. A growing number of studies are exploring the advantages and roles of mobile technologies, yet challenges to initiating the use of mobile technology to teach patients in acute and progressive care clinical settings remain.

The purpose of this article is to present our experience teaching staff nurses to incorporate an electronic tabletbased patient education tool into the clinical workflow in acute and progressive care settings. We address challenges that were encountered specific to tablet adoption, including communicating the value of using mobile technology, training staff for role responsibilities, and ensuring device-related safety, including unit construction and infrastructure for storage as well as patient safety issues such as preventing cross-contamination and limiting

Despite evidence supporting tablet use, the most commonly reported barriers to making evidence-based change included insufficient time and lack of administrative support. access to protected health information. Because our experience of initiating the use of electronic tablets for patient education was stymied by these adoption challenges, many of which required resolution before we could conduct a patient outcomes focused quality improvement study, we present these lessons learned as a critical precursor to using tablets in the clinical setting.

\section{Approach for Implementation}

Our approach for preparing staff to implement iPadbased patient education began from a shared governance perspective. Our administrative leadership team was aware that, despite evidence supporting tablet use, the most commonly reported barriers to making evidencebased change included insufficient time and lack of administrative support. ${ }^{22}$ To address these concerns head-on, nurse leaders engaged in the implementation efforts for tablet-based patient education from the start. Unit nurse managers and the clinical operations director used this opportunity to create a practice environment that supported professional nursing practice and highquality care through the implementation of the iPad (Apple Inc) as an innovative method of delivering patient education. The leadership team took steps to ensure that staff would have the necessary time and tools to incorporate evidence-based iPad education as standard practice and to integrate this new approach into existing workflows. ${ }^{22}$

As a first step, unit-based committee leaders from the education and quality improvement committees identified staff to engage in the "iPad unit champion" role. These nurse champions participated in preliminary training sessions with the research team to gain an understanding of the expectations of the role and their responsibility for creating cohesive staff nurse teams or "work groups. ${ }^{23}$ Next, the champions led their respective teams through the implementation process using a structured approach, described in detail later, that included communicating the value of the project, training staff on workflow integration using a competencybased approach, and managing the logistics of iPad device care by using process standards and developing operating procedures. Throughout each of these steps in implementation, the involvement of leadership conveyed an intimate understanding of the challenges faced by front-line staff regarding the implementation process and the time involved to implement a practice change successfully. This level of involvement allowed nursing leaders to create a consistent, supportive, and positive message throughout the course of the all-staff roll out. The message coming from the leadership team contributed to the culture of engagement necessary to support adoption of evidence-based educational approaches and was instrumental in securing the frontline nurses' view of the importance of their contribution to the implementation of the new patient education process.

In addition to strong, visible leadership support, staff development for tablet implementation was designed with 3 major aims: (1) to establish the value of iPad educational delivery for patients and providers; (2) to formulate the roles, responsibilities, competencies, and workflow integration for all members of the care team; and (3) to develop the processes and procedures for safety, including device protection, cleaning, storage, charging, and software version maintenance of the iPads. The overall goal for implementation was to ensure a high level of staff competency for use of the device and to integrate iPad-based education into the usual unit workflow.

\section{Defining the Value}

Although nurses on the iPad-based education platform design team had participated in 2 years of research, 


\section{Table 1 Constructing a value message for patients, health system, and staff}

Patient

Centralizes documentation for improved communication across patient care transitions

Standardizes educational options across the health care system using guidelinebased content for heart failure
Health system

Centralizes documentation for improved communication across patient care transitions

Meets requirements for The Joint Commission accreditation for patient-centered education

Staff

Centralizes documentation for improved communication across patient care transitions

Saves time for documentation of learning outcomes; content is on touch screen and nurse can focus on self-management skills

Increases opportunities for engagement of patients and their families through skill-based learning

Meets regulatory (Centers for Medicare and Medicaid Services) requirements for evidence-based care metrics

\begin{tabular}{lcc}
\hline $\begin{array}{c}\text { Establishes individual-level learning } \\
\text { priorities to develop and carry out } \\
\text { education plan }\end{array}$ & $\begin{array}{c}\text { Assesses and documents primary care } \\
\text { provider and transition of care to } \\
\text { home }\end{array}$ & $\begin{array}{c}\text { Provides performance review incen- } \\
\text { tives for participation in dissemina- } \\
\text { tion of reports }\end{array}$ \\
\hline $\begin{array}{c}\text { Creates opportunity for communication } \\
\text { between inpatient and outpatient care } \\
\text { settings }\end{array}$ & $\begin{array}{c}\text { Assesses and documents risk for } \\
\text { readmission; assesses educational } \\
\text { precursors to readmission }\end{array}$ & $\begin{array}{c}\text { Recognizes peer recognition and indi- } \\
\text { vidual incentives offered through } \\
\text { Team Challenge }\end{array}$ \\
\hline $\begin{array}{c}\text { Improves care team's awareness of } \\
\text { baseline self-care knowledge and new } \\
\text { priorities for learning }\end{array}$ & $\begin{array}{c}\text { Provides skill-based learning tool for } \\
\text { improved medication reconciliation }\end{array}$ & $\begin{array}{c}\text { Measures and evaluates patients' learn- } \\
\text { ing outcomes (not simply delivery of }\end{array}$ \\
\hline
\end{tabular}

development, and feasibility testing, the majority of unit and clinic staff had not participated in this preimplementation phase. As a result, most were not aware of the value and advantages of the new approach for delivery of patient education. To prepare for changes in clinical practice patterns, the implementation team focused first on defining the value of iPad-based education for patients with regard to educational outcomes, ${ }^{3}$ second on defining the value for the health system with regard to regulatory and quality outcomes, ${ }^{24}$ and last on defining the added value for staff with regard to continuing education and professional development opportunities (Table 1). The implementation team worked first with unit champions to describe and discuss the advantages of the iPad-based education method ${ }^{25,26}$ for patients, families, nurses, and the health system's quality improvement initiatives. Through these discussions, common questions from the staff were addressed and answers to key questions were found before the full staff rollout. Process questions, such as how the documentation interface would work with the electronic health record and how the staff incentives for patient enrollment and participation would be distributed among the team, were clarified and answered. The value message was then condensed into clear, concise, and easily communicated content and was delivered using a series of combined approaches.

\section{Communicating the Value}

Implementation teams leaned heavily on change theory $y^{27,28}$ and our shared governance model to formulate and disseminate the value message across clinical areas to staff, ancillary support personnel, and the broader health system leadership team. The first role of unitbased champions was development and presentation of the value message. Nurse champions worked with nurse managers, ancillary staff, student nurses, and members of the iPad-based patient education research team to design, evaluate, and revise the presentation of materials for the all-staff rollout. Using a PowerPoint presentation format allowed multiple educational team members to "show" and discuss the value points and implementation process with various audiences across different units, affiliated hospital settings, and in clinics, without Defining and communicating the value message was key to success of the project: improving patients' educational outcomes, health system quality and satisfaction measures, and staff opportunities for professional development.

losing the key points of the message. The presentation was split into 2 parts for brevity, given the time constraints of the audience and busy clinical practice environment. Practice presentations were done first within 


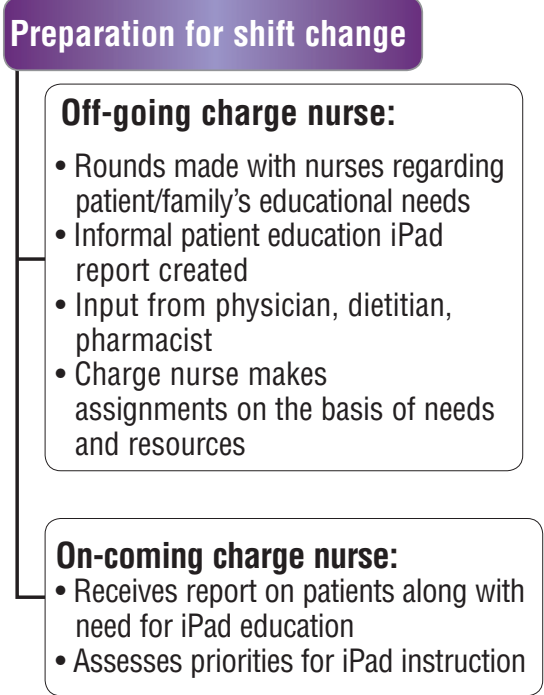

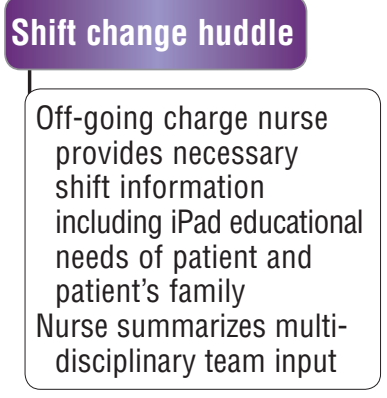

Oncoming shift

Nurse with initial assessment evaluate:

- Family presence

- Readiness of patient and patient's family

- Place on white board as a goal for the shift to enable the team to gauge understanding

Nurse to initiate

- Information required to perform the learning assessments

- Move patient and patient's family into the assessment

- Set up access to the educational portion

- Provide information about where the process halted to the oncoming shift during handoff

- Oncoming shift to provide access to patient and patient's family for completion of the educational process

Figure 1 Integrated iPad-based education workflow.

the team, so that all members felt comfortable sharing the value of the iPad-based educational program, and then across acute and progressive care nurse groups.

Staff incentives were designed to add to the intrinsic value of improved patient care and to smooth the change process during implementation of the innovation..$^{29} \mathrm{We}$ developed an tablet team challenge, using incentives to reward nurses' educational assessment and teaching skills, and expertise in the use of the iPad system. Shared accountability for patient and health system outcomes was established between nurse leaders and frontline staff to ensure that adoption of the evidence-based practice project would be supported and rewarded by the nurse manager team and the director for nursing operations on the unit. ${ }^{23}$ To ensure wide dissemination and to provide nurses opportunities for professional development, nurse champions presented monthly updates and quarterly reports about the iPad patient education program to regular leadership meetings, best practice committee meetings, and unit-based staff meetings. These reports included implementation progress reports, patient education documentation reports used for accreditation purposes by the health system, patient learning outcomes, and selected quality metrics submitted to the Centers for Medicare and Medicaid Services for public reporting and regulatory purposes. Last, to provide incentives for personal development goals in annual peer evaluation and performance reviews, these presentations and involvement in the iPad patient education implementation team were tracked and used by the leadership team to reward and recognize the efforts of staff in personal professional development.

\section{Formulating Roles and Competencies}

The responsibility for educating patients and preparing them to manage a complex medical regimen following discharge falls not only to the nurse but also to other members of the health care team. New Joint Commission Standards for educational documentation emphasize this fact, ${ }^{30}$ and yet while "all" are responsible, those actually accountable often narrows down to only a few. To ensure that responsibility for delivery, documentation, and evaluation of learning outcomes for discharge preparedness was dispersed to the multidisciplinary care team, the implementation goals included development of competency-based skills for each role and caregiver discipline represented in the workflow. In addition, the design of the workflow itself represented an integration of all members of the multidisciplinary team (Figure 1).

We defined roles and responsibilities for all members of the multidisciplinary team who contribute to the patient education process, including staff nurses, advanced 


\section{Table 2 Educational content}

Topic

Content

\begin{tabular}{ll}
\hline Medications & Virtual pill-box-filling exercise \\
\hline Symptoms & Symptom recognition links from the American Association of Heart Failure Nurses \\
\hline Activity & $\begin{array}{c}\text { Learning checks for safe activity progression; links to the American Association for Cardiopulmonary } \\
\text { Rehabilitation }\end{array}$ \\
\hline Diet & $\begin{array}{c}\text { Learning checks for managing sodium and sugar in the diet; nutrition label reading skill exercises; } \\
\text { links to American Heart Association's dietary modification for cardiovascular disease }\end{array}$ \\
\hline $\begin{array}{l}\text { What to report } \\
\text { List of symptoms and symptom changes that should be reported, as well as urgency for notifying the } \\
\text { provider }\end{array}$ \\
\hline $\begin{array}{l}\text { Whom to contact } \\
\text { nurse practitioner }\end{array}$ \\
\hline $\begin{array}{l}\text { Additional information } \\
\text { Website links offered to professional organizations, patient advocacy groups and social networking } \\
\text { sites such as "Patients Like Me" }\end{array}$
\end{tabular}

practice nurses, pharmacists, dieticians, ancillary support staff, patient resource managers, physicians, and patients and families. We asked each discipline, including patient advocates, for implementation responsibilities specific to their role in heart failure education. As shown in Table 2, the content for predischarge patient education was based on input from each discipline and was reviewed for approval by the team.

The role of care nurses for initiating patient access and entry into the predischarge education program is supported throughout the inpatient stay by nursing assistants, unit secretaries, charge nurses, and all members of the care team. After accessing the system using secure log-ins, a health literacy evaluation (REALM ${ }^{31}$ ) and a measure of patient activation, or the self-reported confidence to engage in self-management health behaviors (PAM-13 ${ }^{32}$ ), is completed. These scores are generated by the system and displayed for the provider to use to tailor subsequent education to the patient's learning preferences and needs. Providers can then start survey pages so that patients can navigate the iPad independently, completing surveys to assess likelihood for medication nonadherence, symptom presentation patterns, and self-management skills. Following completion of assessments, the educator logs back in to the system to launch the education modules.

The role of patients and families is to engage in selfpaced, self-directed learning using the iPad program; however, the extent of engagement is patient-dependent and highly variable. Actual use of the program and extent of engagement with the skill-based tools and educational content is evaluated using the "check your knowledge" questions at the end of each topic segment. As a result of the scoring mechanism for each content area, the care team is aware of areas that need reinforcement before discharge. Even if patients are hesitant to communicate openly about learning needs or weaknesses, the responsibility of the care team is to interpret the patient scores on learning checks, and provide supplementary content, support, and encouragement for eventual adoption of evidence-based self-management skills and behaviors.

Throughout the admission or clinic visit, the role of the nurse and multidisciplinary care team is to offer the patient multiple opportunities to complete education modules and assessments. Immediately before discharge, the patient completes surveys to assess satisfaction with the education received and confidence for implementing these skills at home. The iPad system generates a report of the Educating patients to manage complex regimens following discharge is a team responsibility; an electronic tablet-based system can help track patient progress. aggregate as well as individual-level learning goals, goal achievement, and medication management skills. The report is included in the medical record and also used in aggregate to evaluate program participation and outcomes. Individual-level information is available to guide care across settings, including hospital, clinic, community, and home.

The role of physicians in patient education has traditionally been reactive rather than proactive. That is, physicians are comfortable answering patient or family questions about a care plan, but only recently have physicians initiated the educational process. The rationale 
for this is multifactorial, but likely stems from a combination of (1) a perceived lack of time, (2) the absence of instruction received by a physician on the importance of patient education in his or her own medical training, and (3) the presumption that the responsibility of patient education typically resides with other caregivers.

Medical students, in contrast, occupy unique positions in the medical team in that they are "grouped" within the physician sphere but are actively learning as students. Relative to their physician counterparts, they have fewer patient responsibilities and therefore greater amounts of time to dedicate toward direct patient interaction. The patient education process is also likely to be of significant educational interest and value to the student, and it could reinforce disease pathology, symptoms, clinical presentation, and course, along with treatment methods.

\section{Integrating iPad Education Into Usual Care Workflo}

Integrating the iPad technology into the workflow for usual care delivery posed challenges. Traditional written educational materials were replaced with iPads to deliver patient education, and, as a result, each step in the workflow for patient education, from ordering educational materials from hospital procurement (materials management services) to completion of patient learning checks for each specific content area, was redesigned (Figure 1). Our team no longer defined
The role of the nurse is to offer patients multiple opportunities to complete educational goals; the iPad generates a report of the aggregate and individual-level learning goals, goal achievement, and medication management skills. "education notebook given to the patient" as a sufficient criterion for completion of educational objectives. Instead, the workflow reflected assessment of the patient-reported learning priorities, evaluation of the patient's literacy level and competencies, and integration of skill-based learning techniques into the course of daily patient care. Although the change represented significant advances in implementing evidence-based practice for patient education, the change required effort and ingenuity on the part of the implementation team and champions to be successful.

As outlined in Figure 1, each member of the care team had a role in the workflow change. Nurses and physicians as well as nutritionists, pharmacists, and physical therapists were responsible for identifying patients who required new or additional skill reinforcement for self-management of the heart failure regimen. A review of patients' status toward achievement of educational goals was integrated into charge nurse report and bedside report among all staff.

The skills competency checklist (Figure 2) and its accompanying training video and slide presentations were used to reinforce the workflow integration and highlight opportunities for time savings and education documentation efficiencies. For example, the time previously spent by nurses distributing flat, noninteractive written instructions in the education workbook transitioned to time spent facilitating patient engagement with interactive skill-based tools and picture-driven videos on the iPad. The scope and breadth of educational information available from credible professional organizations and patient advocacy groups in literacyappropriate format was also an advantage, allowing patients to browse selected links for additional information of their choice. As noted by nurses, house officers, and ancillary staff colleagues, the entire care team learned something from the online information available and accessible to patients through the iPad education links.

Importantly, the workflow was not seen as "ending at discharge," but was phased into patient care processes that continued throughout the acute stay and into the care transition period to home, the follow-up phone call, and later to the 1-week and 1- to 3-month clinic visits. The team developed a recognition and appreciation for the extent and complexity of the work required for patients to learn and adopt new self-care behaviors—an extension of the change in the medical record documentation from "educational materials given" to "self-management skills mastered" and all the way to "self-management skills adopted."

\section{Developing Safe Processes and Procedures for Device Use}

Integrating the iPads into the workflow of the unit required defining processes and standard procedures for safe care and storage of the devices themselves. Device storage and charging instructions, including infection control measures, were addressed in a written process standard that was submitted by the implementation team and reviewed for approval by the department's 


\begin{tabular}{|c|c|c|c|c|c|c|}
\hline Category & & Performance criteria & $\begin{array}{l}\text { Preceptor } \\
\text { evaluation } \\
\text { (date/initials) }\end{array}$ & VK & $\begin{array}{l}\text { Validation } \\
\text { completed } \\
\text { (date/ } \\
\text { initials) }\end{array}$ & Comments \\
\hline $\begin{array}{l}\text { Components } \\
\text { of training/ } \\
\text { skill validation }\end{array}$ & $\begin{array}{l}1 . \\
2 .\end{array}$ & $\begin{array}{l}\text { View skill-based learning slides ( } 1 \text { and } 2) \\
\text { View Agency for Healthcare Research and Quality } \\
\text { video on performing teachback } \\
\text { Check off by trainer on the iPad test site }\end{array}$ & $\begin{array}{l}\text { 1. } \\
\text { 2. } \\
\text { 3. }\end{array}$ & & & \\
\hline $\begin{array}{l}\text { Assessment of } \\
\text { patient }\end{array}$ & $\begin{array}{l}4 . \\
5 . \\
6 .\end{array}$ & $\begin{array}{l}\text { Perform patient learning assessment } \\
\text { Engage patient /family in assessment } \\
\text { Perform health literacy evaluation (REALM) }\end{array}$ & 1. & & & \\
\hline $\begin{array}{l}\text { Planning for } \\
\text { procedure }\end{array}$ & $\begin{array}{l}1 . \\
2 .\end{array}$ & $\begin{array}{l}\text { Obtain iPad from secure charging box } \\
\text { Input patient's name, medical record number, } \\
\text { birthdate, admission date, and room number }\end{array}$ & 1. & & & \\
\hline $\begin{array}{l}\text { Interventions/ } \\
\text { skills }\end{array}$ & & $\begin{array}{l}\text { 1. Log patient in to Heart at Home using iPad } \\
\text { 2. Register patient in iPad and complete the } \\
\text { following: } \\
\text { - Risk assessment } \\
\text { - Medical Home } \\
\text { 3. Assist patient with survey completion } \\
\text { - Initial assessment } \\
\text { - Predischarge assessment } \\
\text { 4. Provide education using video and slides, including } \\
\text { check-your-knowledge questions } \\
\text { 5. Discharge patient from system } \\
\text { 6. Print reports and send to medical records }\end{array}$ & 1. & & & \\
\hline Patient safety & 1. & $\begin{array}{l}\text { Ensure that patient has the skills and knowledge for } \\
\text { self-care } \\
\text { Ensure that nurse is logged out before handing iPad to } \\
\text { patient }\end{array}$ & 1. & & & \\
\hline Evaluation & 1. & $\begin{array}{l}\text { Assess learning using teach-back. Key: Open-ended } \\
\text { questions, patient repeat in own words, clarify } \\
\text { misunderstanding } \\
\text { Formulate and communicate plan for meeting additional } \\
\text { learning needs based on teach-back assessment }\end{array}$ & 1. & & & \\
\hline
\end{tabular}

Figure 2 Nurse competency checklist for iPad education.

Abbreviation: VK, verbalized knowledge.

clinical practice council. The process standard was written to facilitate the change from delivery of written educational materials and television video options to iPad technology and integration of hand-held device use into the workflow for patient care in the clinical areas. Comprehensive, simple instructions for care and use of the devices were included in a process standard so that anyone in the specified roles could access instructions and use the devices safely.

\section{Tracking and Security}

Using iPads in hospital and outpatient clinic settings for patients presented challenges for security and safety of the devices. Protecting the investment in devices was an important consideration to ensure the long-term viability and sustainability of the program. In partnership with the local campus police department, each iPad was engraved in an area where it could be seen through the protective case that had been purchased and applied to protect the equipment. The serial numbers for each iPad were registered with the police department. This step proved to be important in reducing confusion between hospital-owned iPads and privately owned iPads. In addition, tracking capability for each device was put in place by activating the "find my iPad" function, available in any area in which the technology was used. Within the clinical 


\section{Table 3 Protocol for cleaning and storage of iPad}

Responsible personnel

Nursing assistant

\section{Process and procedure}

Before beginning each shift, complete iPad checklist:

Verify the charge is $100 \%$.

Check the cleanliness and adhesive of the screen protector.

Verify the secure closure of the drop-resistant case to the back and front of iPad.

Preload new patient names and room numbers for patients ready to participate in education, as indicated from rounds.

Any team member conducting Before each patient interaction:

an iPad educational session
Clean your hands with gel, foam, or soap and water before and between each patient's interaction with the iPad.

Using a disinfectant wipe, clean the outside of the iPad device from top to bottom, then from left to right.

Use a second disinfectant wipe if the device is grossly contaminated, making sure all crevices are wet.

After all visible surfaces and crevices are wet, allow iPad to air dry before beginning the interactive session.

For patients on isolation precautions, place the iPad in a plastic baggie and ziplock the baggie before use. Remove after each patient contact and clean as above. Remember to provide a stylus for patients on isolation who are using the iPad. areas, the iPads were assigned each day to a care nurse. In ambulatory areas, a sign-in/out log was used to track which nurse and patient were currently using the device.

\section{Charging and Storage}

A checklist for cleaning and appropriate nightly storage was developed to ensure that the iPads were ready and available for patients to use each day (Table 3). Nurses collaborated with the pharmacy department to repurpose an empty compartment in the Omnicell secure drug distribution system to securely store and electronically log iPad access. Although the Omnicell offered advantages in security and electronic tracking, a barrier was encountered in that the Omnicell units did not allow for proper venting or for electrical access for charging the iPads. The long battery life and resting power function of the iPads allowed night-charging only, and a locked charging station was designed that could be easily managed by the charge nurse on day shift. Wide file racks were purchased from a local office supply store to separate the iPads and to protect the iPads from damage (Figure 3). Nursing assistants facilitated the iPad counts at shift change and verified the charge status of each iPad, ensuring that devices were properly stored each night in the power station lockbox.

\section{Infection Control}

The patient risk for cross-contamination from shared iPad use was addressed in 3 ways: (1) requesting protocols

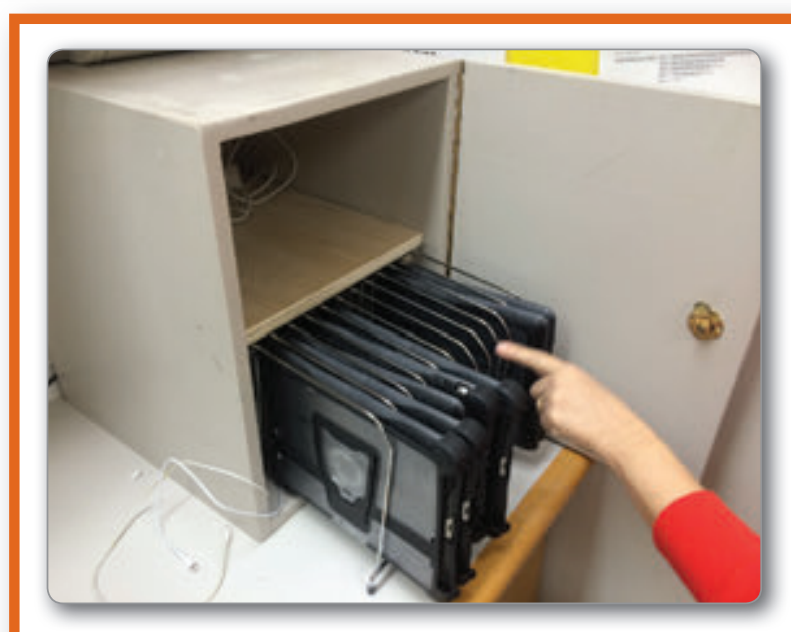

Figure 3 Safe storage solutions for the iPads.

from oncology clinical areas with previous experience using iPads in immunocompromised patients, (2) meetings with infection control, and (3) review of the literature. Though definitive research was not available, expert consensus after these steps indicated that topical cleaners were effective in reducing microbial colonization and that the use of occlusive baggies was effective in the case of patients on isolation precautions. The iPad implementation team found that the iPads functioned properly within a clear plastic, sealable bag. A rubber-tipped stylus or the eraser of a pencil could be used with the iPad's touch screen, either with or without the plastic bag protector. Sani-cloth disinfectant wipes (Sani Professional) were 
used between patients to minimize cross- contamination risk (Table 3). In the hospital units, nursing assistants took responsibility for leading device cleaning and working in collaboration with the infection control committee to conduct intermittent audits of cleanliness.

\section{Evaluating Implementation Processes}

Nurses' acceptance of the implementation of electronic health record systems has been studied, but nurses' acceptance of Internet technology being used by patients in a health care setting has not been reported. In evaluating iPad-based education, both the nurse and the patient must be considered as users. Unlike the traditional technology acceptance model, ${ }^{33,34}$ which evaluates a single user, tablet-based patient education has 2 types of users who must be concentrically evaluated, the nurse and the patient. For our project, the Davis mode ${ }^{35}$ more aptly focuses on "perceived usefulness" and "perceived ease of use" for both users. Therefore, using stem questions similar to those from Davis's model, a Likert and open-text type of survey was developed and administered to nurses on the unit before they worked with their first patient on the iPad. The preimplementation 10-question survey was collected anonymously by using SurveyMonkey and included 9 questions asking nurses how the iPads fit into their workflow and how they thought their patients would receive the technology. An initial response rate of $62 \%$ $(n=28)$ was obtained. A majority of the nurse responses were positive regarding "perceived ease of use"; however, more neutrally divided responses were received to the "perceived usefulness" questions on productivity. The implementation team responded by creating a clearer, more comprehensive presentation of the value message for the full staff rollout.

At the end of the survey, a free-text field allowed for written suggestions and concerns. Of those who responded, concerns were raised regarding acceptance of the technology by patients, capabilities of patients using the technology, and the stamina of patients to complete "lengthy" questionnaires. Apprehensions about time to teach the technology and interruptions of care also were conveyed. To address these anxieties, the implementation team incorporated existing evidence on acceptance by elderly users of the technology into the staff development training materials.

Limitations of the evaluation included the timing of the preimplementation surveys and the short window of time allowed for the pretest evaluation. The preimplementation survey was distributed on a rolling basis as nurse users were available for training and before working with their first patient. Revisions to the staff development training program were then integrated before the full staff rollout. A final limitation of the evaluation was the design of comparisons of survey results from before to after implementation. To facilitate truthful responses, the respondents were blinded; only an Internet provider address, date, and time were captured for each survey completed. With the normal staff changes that occur on a unit, and because of the confidential nature of the survey, comparing the same respondents' responses to the preimplementation and postimplementation surveys was not possible. However, both the preimplementation and postimplementation surveys offered valuable feedback for the team to evaluate the general perceptions that nurses had about using the iPads and how integration affected workflow and patient care.

\section{Conclusions}

Technology-based learning tools, such as tablet applications, may be used in acute and progressive care settings to improve patients' readiness for hospital discharge. However, integrating these devices into usual care delivery processes and workflows presents challenges for nurses. Staff development initiatives that prepare staff to use tablets by engaging leadership in “on-boarding” staff, establishing the value of iPad educational delivery for patients and providers, formulating the roles, responsibilities, competencies, and workflow integration for all members of the care team, and developing the processes and procedures for safe device use may improve the experience of adopting tablets. $\mathrm{CCN}$

Financial Disclosures

This program is funded by a grant from The Duke Endowment foundation (TDE Grant \#6304-SP) and the Duke Heart Center, Center of Excellence. Dr Abernethy has received research funding from DARA Biosciences, GlaxoSmithKline, Celgene, Helsinn Therapeutics, Dendreon, Kanglaite, Bristol-Myers Squibb, and Pfizer, as well as federal sources; these funds are all distributed to Duke University Medical Center to support research including salary support for Dr Abernethy. Pending industry-funded projects include Galena Biopharma and Insys Therapeutics. Since 2012, Dr Abernethy has had consulting agreements with or received honoraria from (> $\$ 5000$ annually) Bristol-Myers Squibb and ACORN Research, and she has corporate leadership responsibility in Flatiron Health Inc (health information technology [HIT] company; chief medical office and senior vice president), athenahealth Inc (HIT company; director), Advoset LLC (education company; owner), and Orange Leaf Associates LLC (IT development company; owner).

\section{elesters}

Now that you've read the article, create or contribute to an online discussion about this topic using eLetters. Just visit www.ccnonline.org and select the article you want to comment on. In the full-text or PDF view of the article, click "Responses" in the middle column and then "Submit a response." 


\section{(c) olinore}

To learn more about patient education, read "Preoperative Education on Postoperative Delirium, Anxiety, and Knowledge in Pulmonary Thromboendarterectomy Patients" by Chevillon et al in the American Journal of Critical Care, March 2015;24:164-171. Available at www. ajcconline.org.

\section{References}

1. Bull MJ, Hansen HE, Gross CR. A professional-patient partnership model of discharge planning with elders hospitalized with heart failure. Appl Nurs Res. 2000;13:19-28.

2. Horwitz LI, Moriarty JP, Chen C, et al. Quality of discharge practices and patient understanding at an academic medical center. JAMA Intern Med. 2013;173(18):1715-1722.

3. Greysen SR, Khanna RR, Jacolbia R, Lee HM, Auerbach AD. Tablet computers for hospitalized patients: a pilot study to improve inpatient engagement. J Hosp Med. 2014;9(6):396-399.

4. Farmer A, Toms C, Hardinge M, Williams V, Rutter H, Tarassenko L. Self-management support using an Internet-linked tablet computer (the EDGE platform)-based intervention in chronic obstructive pulmonary disease: protocol for the EDGE-COPD randomised controlled trial. BMJ Open. 2014;4:e004437.

5. Centers for Medicare and Medicaid Services Research, Statistics, Data and Systems. 2013. http://www.cms.gov/Research-Statistics-Data-and -Systems/Statistics-Trends-and-Reports/MedicareMedicaidStatSupp /2013.html. Accessed October 26, 2015.

6. Williams MV. A requirement to reduce readmissions: take care of the patient, not just the disease. JAMA. 2013;309:394-396.

7. Gold KS. Crossing the quality chasm: creating the ideal patient care experience. Nurs Econ. 2007;25:293-295, 298

8. Lukas CV, Holmes SK, Cohen AB, et al. Transformational change in health care systems: an organizational model. Health Care Manage Rev. 2007;32:309-320

9. Yancy CW, Jessup M, Bozkurt B, et al. 2013 ACCF/AHA Guideline for the Management of Heart Failure: a report of the American College of Cardiology Foundation/American Heart Association Task Force on Practice Guidelines. J Am Coll Cardiol. 2013;62(16):e147-e239.

10. Patterson ME, Hernandez AF, Hammill BG, et al. Process of care perfor mance measures and long-term outcomes in patients hospitalized with heart failure. Med Care. 2010:48:210-216.

11. PQA Measures Used by CMS in the STAR ratings. 2012. http://pqaalliance .org/measures/cms.asp. Accessed October 26, 2015.

12. Regalbuto R, Maurer MS, Chapel D, Mendez J, Shaffer JA. Joint Commission requirements for discharge instructions in patients with heart failure: is understanding important for preventing readmissions? J Card Fail. 2014;20:641-649.

13. Cant RP, Cooper SJ. Simulation in the Internet age-the place of Webbased simulation in nursing education: an integrative review. Nurse Educ Today. 2014;34(12):1435-1442

14. McDermott MS, While AE. Maximizing the healthcare environment: a systematic review exploring the potential of computer technology to promote self-management of chronic illness in healthcare settings. Patient Educ Couns. 2013;92:13-22.

15. Free C, Phillips G, Galli L, et al. The effectiveness of mobile-health technology-based health behaviour change or disease management interventions for health care consumers: a systematic review. PLoS Med. 2013;10:e1001362.

16. Kaufman N. Using health information technology to prevent and treat diabetes. Diabetes Technol Ther. 2013;15(suppl 1):S60-S74.

17. Nogueira PC, de Carvalho Nagliate P, de Godoy S, Rangel EM, Trevizan MA, Mendes IA. Technology use for health education to caregivers: an integrative review of nursing literature. Appl Nurs Res. 2013;26:101-104.

18. Abernethy AP, Etheredge LM, Ganz PA, et al. Rapid-learning system for cancer care. J Clin Oncol. 2010; 28(27):4268-4274.

19. Sherrard H, Struthers C, Kearns SA, Wells G, Chen L, Mesana T. Using technology to create a medication safety net for cardiac surgery patients: a nurse-led randomized control trial. Can J Cardiovasc Nurs. 2009;19(3):9-15.

20. Granger BB, Bosworth HB. Medication adherence: emerging use of technology. Curr Opin Cardiol. 2011;26:279-287.

21. Osborn CY, Mayberry LS, Wallston KA, Johnson KB, Elasy TA. Understanding patient portal use: implications for medication management. JMed Internet Res. 2013;15:e133.
22. Melnyk BM, Fineout-Overholt E, Gallagher-Ford L, Kaplan L. The state of evidence-based practice in US nurses: critical implications for nurse leaders and educators. J Nurs Adm. 2012;42:410-417.

23. Kupperschmidt BR. Making a case for shared accountability. J Nurs Adm. 2004;34:114-116.

24. Gardetto NJ, Carroll KC. Management strategies to meet the core heart failure measures for acute decompensated heart failure: a nursing perspective. Crit Care Nurs Q. 2007;30:307-320.

25. Mahramus T, Penoyer DA, Frewin S, Chamberlain L, Wilson D, Sole ML. Assessment of an educational intervention on nurses' knowledge and retention of heart failure self-care principles and the Teach Back method. Heart Lung. 2014;43:204-212.

26. White M, Garbez R, Carroll M, Brinker E, Howie-Esquivel J. Is "teachback" associated with knowledge retention and hospital readmission in hospitalized heart failure patients? J Cardiovasc Nurs. 2013;28:137-146.

27. Weiner BJ. A theory of organizational readiness for change. Implement Sci. 2009;4:67.

28. Gallagher-Ford L, Fineout-Overholt E, Melnyk BM, Stillwell SB. Evidencebased practice, step by step: implementing an evidence-based practice change. Am J Nurs. 2011;111:54-60.

29. Varkey P, Antonio K. Change management for effective quality improvement: a primer. Am J Med Qual. 2010;25:268-273.

30. Hospital National Patient Safety Goals. 2012. http://www.jointcommission .org/standards information/npsgs.aspx. Accessed July 17, 2013.

31. Griffin JM, Partin MR, Noorbaloochi S, et al. Variation in estimates of limited health literacy by assessment instruments and non-response bias. J Gen Intern Med. 2010;25(7):675-681.

32. Hung M, Carter M, Hayden C, et al. Psychometric assessment of the patient activation measure short form (PAM-13) in rural settings. Qual Life Res. 2013;22:521-529.

33. Kowitlawakul Y. The technology acceptance model: predicting nurses' intention to use telemedicine technology (eICU). Comput Inform Nurs. 2011;29(7):411-418.

34. Escobar-Rodriguez T, Romero-Alonso MM. Modeling nurses' attitude toward using automated unit-based medication storage and distribution systems: an extension of the technology acceptance model. Comput Inform Nurs. 2013;31:235-243.

35. Davis FD. Perceived usefulness, perceived ease of use, and user acceptance of information technology. MIS Q. 1989;13:319-340. 


\section{Implementing Electronic Tablet-Based Education of Acute Care Patients}

Tenita Sawyer, Monica J. Nelson, Vickie McKee, Margaret T. Bowers, Corilin Meggitt, Sarah K. Baxt, Delphine Washington, Louise Saladino, E. Philip Lehman IV, Cheryl Brewer, Susan C. Locke, Amy Abernethy, Catherine L. Gilliss and Bradi B. Granger

Crit Care Nurse 2016;36 60-70 10.4037/ccn2016541

(C2016 American Association of Critical-Care Nurses

Published online http://ccn.aacnjournals.org/

Personal use only. For copyright permission information:

http://ccn.aacnjournals.org/cgi/external_ref?link_type=PERMISSIONDIRECT

\section{Subscription Information}

http://ccn.aacnjournals.org/subscriptions/

\section{Information for authors}

http://ccn.aacnjournals.org/misc/ifora.xhtml

\section{Submit a manuscript}

http://www.editorialmanager.com/ccn

\section{Email alerts}

http://ccn.aacnjournals.org/subscriptions/etoc.xhtml 